\title{
Simulating the development and progression of Chronic Kidney Disease and osteoporosis in people living with HIV
}

\author{
Silvano Adami ${ }^{1}$, Paolo Maggi ${ }^{2}$, Vincenzo Montinaro ${ }^{3}$, Massimiliano Povero ${ }^{4}$, \\ Lorenzo Pradelli ${ }^{4}$, Rita Bellagamba ${ }^{5}$, Paolo Bonfanti ${ }^{6}$, Antonio Di Biagio ${ }^{7}$, \\ Stefano Rusconi ${ }^{8}$, Francesco Maria Di Campli ${ }^{9}$, Giuseppe Forastieri ${ }^{9}$, Michele Mancini ${ }^{9}$ \\ Rheumatology, University of Verona \\ Institute of Infectious Disease, University of Bari \\ Division of Nephrology, University of Bari, Polyclinic \\ AdRes HE \& OR, Turin, Italy \\ National Institute for Infectious Diseases L. Spallanzani, Rome, Italy \\ AO Provincia di Lecco - Ospedale "A.Manzoni", Lecco, Italy \\ Clinica Malattie Infettive. IRCCS Azienda Ospedaliera Universitaria San Martino - IST Istituto Nazionale di Ricerca \\ sul Cancro di Genova, Italy \\ 8 Divisione Clinicizzata di Malattie Infettive. Dipartimento di Scienze Biomediche e Cliniche "Luigi Sacco". \\ Università degli Studi di Milano \\ 9 ViiV Healthcare
}

\begin{abstract}
The "chronicization" of HIV infection brings about a growing necessity to attentively evaluate current and potential complications when prescribing the individual therapeutic regimen. Starting from this need, we developed two HIV-comorbidity simulators that, basing on the evidence available in medical literature and starting from the current clinical and demographic features of the individual patient, project and compare the risks of developing and worsening of nephropathy and osteopathy associated with possible ARV regimens. These simulators are embedded in a desktop, user-friendly software thought to be used by the treating physician during prescription discussion with his/her patients, in order to highlight expected clinical outcomes and healthcare resource consumption that may differ according to the therapeutic strategy selected. In this article we present the sources and methods used in developing the mathematical models, alongside a set of examples and the results of cohort-level validation runs.
\end{abstract}

\section{Keywords}

HIV; Chronic Kidney Disease; Osteoporosis

\section{INTRODUCTION}

Infection with Human Immuno-deficiency Virus (HIV) may be considered one of the most challenging epidemics faced by health systems globally. In 2012, UNAIDS estimated a global prevalence of around 35.3 million people living with HIV (PLHIV). This number is increasing due to the availability of antiretroviral therapy (ART) and, mutually, mortality due to new infections is evidently declining across the globe [1].

Indeed, in the current era, most patients taking HAART achieve full and sustained virologic suppression; however, HAART does not restore full health in PLHIV, who face increased risk of several non-AIDS complications [2], including cardiovascular, renal, and bone disease.

Treating clinicians have to deal with this evolution in the challenges posed by HIV, and redefine aim and tools of HIV infection management. In particular, there is a growing necessity to attentively evaluate current and potential complications when prescribing the individual therapeutic regimen. Starting from this need, we developed two HIV-comorbidity simulators that, basing on the evidence available in medical literature and starting from the current clinical and demographic features of the individual patient, project and
Corresponding author Massimiliano Povero m.povero@adreshe.com

\section{Disclosure}

This study was funded by an unconditional grant from ViiV Healthcare s.r.l. 
compare the risks of developing and worsening of nephropathy and osteopathy associated with possible antiretroviral (ARV) regimens. These simulators are embedded in a desktop, user-friendly software thought to be used by the treating physician during prescription discussion with his/her patients, in order to highlight expected clinical outcomes and healthcare resource consumption that may differ according to the strategy selected. The tool offers the possibility of customizing the projection by modifying the input data proposed as default, selected across a deep review of Italian and international literature and submitted for evaluation to a panel of infectious diseases experts.

In this supplement we present the sources and methods used in developing the tool, alongside a set of examples and the results of cohort-level validation runs. 


\section{Nephropathy model}

\section{BACKGROUND - NEPHROPATHY IN PLHIV}

Before the introduction of ART, HIV-associated kidney disease was the third leading cause of End Stage Renal Disease (ESRD) [3] and associated with higher mortality compared to other causes of kidney disease [4]. The incidence of HIV-associated kidney disease markedly decreased after the introduction of ART and any increase in the incidence of kidney disease may be attributed to aging and traditional associated risk factors like diabetes and hypertension [5] and as a side effect of ARTs themselves [6-8]. ARTs are recommended for all symptomatic patients and those asymptomatic with CD4 cell count below $350 / \mu \mathrm{L}$ [9]. Due to highly comparable efficacy between Reverse Transcriptase Inhibitors (RTI) or a ritonavir-boosted protease inhibitor based regimens, the initial choice should be personalized and be based on more than efficacy: co-morbidities, tolerance/safety and economic factors. On the side of RTIs, tenofovir and (emtricitabine or lamivudine) is one recommended option that proved to be more efficacious than other options from the same class like zidovudine/lamivudine [10] or stavudine/lamivudine [11].

However, one major safety concern with tenofovir is the possible negative impact on renal function [12]. Therefore, renal function assessment before and after initiation is critical; and in patients with renal dysfunction, tenofovir is better avoided [9]. This safety concern was observed to a lesser extent with other ARTs [6-8], yet more studied and confirmed with tenofovir [13-15]. In clinical practice, another problem arises regarding assessing the long term renal safety of tenofovir due to higher discontinuation rates with decreasing eGFR [7]. However, tenofovir wasn't proved to be responsible for ESRD [16] and eGFR loss that may be attributed to tenofovir, in a long-term perspective, is relatively mild [17].

Advanced stages of Chronic Kidney Disease (CKD) are devastating for patients and families on one hand and, on the other hand, have major structural and economic impact on the health systems. This is particularly true when patients move to end-stage renal disease with the inevitable necessity of renal replacement by either dialysis or transplantation [18]. Providing the clinical practice with tools able to predict the occurrence or progression of CKD should aid the provision of necessary interventions that may stop or slow the progression to ESRD [19]. Echouffo-Tcheugui et al. systematically searched the literature in June 2012 for existing models predicting occurrence or progression of CKD in different populations [20]. eGFR cut off value $\left(60 \mathrm{ml} / \mathrm{min} / 1.73 \mathrm{~m}^{2}\right)$ was uniformly used to define CKD. Age, sex, body mass index, diabetes status, systolic blood pressure, serum creatinine, a measure of proteinuria, and serum albumin or total protein were the most frequently included predictors. Sadly, despite the need for it, any of CKD risk prediction tools weren't found to be recommended in relevant clinical guidelines. And the impact of possible adoption of such tools in different clinical settings wasn't assessed [20].

Among Echouffo-Tcheugui et al.'s 26 included papers only one that aimed to predict 1-year probability of developing CKD among HIV-infected population [21]. This model only estimates new cases based on an ethnically limited sample, Japanese patients, and only among patients already receiving ARTs. Age, CD4 cell count, diabetes, proteinuria, and eGFR at baseline were the variables found to be independently associated with the incidence of CKD.

Melting all HIV-specific and traditional risk factors in one predictive model of both incidence and progression of CKD up to ESRD and death is our challenge.

\section{RENAL DISEASE EVALUATION DURING BASELINE PERIOD}

The evolution of renal disease during the 3 years of baseline period is defined using a mathematical algorithm that merges evidence from published literature. The calculation, detailed in the next sub-section, takes into account:

- The initial value of eGFR according to baseline patient characteristics (serum creatinine levels, age, sex and race); 


\begin{tabular}{ccll}
\hline Stage & eGFR ${ }^{1}$ & \multicolumn{1}{c}{ Description } & \multicolumn{1}{c}{ Treatment stage } \\
\hline 1 & $90+$ & $\begin{array}{l}\text { Normal KF but urine findings or structural } \\
\text { abnormalities or genetic trait point to KD } \\
\text { Mildly reduced KF, and other findings (as } \\
\text { for stage 1) point to KD } \\
\text { Moderately reduced KF }\end{array}$ & $\begin{array}{l}\text { Observation, control of BP. More on management of } \\
\text { stages 1 and 2 CKD } \\
\text { Observation, control of BP and risk factors. More on } \\
\text { management of stages 1 and 2 CKD } \\
\text { Observation, control of BP and risk factors. More on } \\
\text { management of stage 3 CKD }\end{array}$ \\
4 & $60-89$ & Severely reduced KF & $\begin{array}{l}\text { Planning for end-stage renal failure. More on } \\
\text { management of stages 4 and 5 CKD }\end{array}$ \\
5 & $15-29$ & $\begin{array}{l}\text { Treatment choices. More on management of stages } \\
4 \text { and 5 CKD }\end{array}$ \\
\hline
\end{tabular}

Table I. CKD stages (elaborated from GLCKD 2002)

$\mathrm{BP}=$ Blood Pressure; $\mathrm{KD}=$ Kidney Disease; $\mathrm{KF}=$ Kidney Function

${ }^{1}$ All eGFR values are normalized to an average surface area (size) of $1.73 \mathrm{~m}^{2}$

2 Stage 3 is usually divided in stage 3A (eGFR 45-59) and stage 3B (eGFR 30-44)

\begin{tabular}{ccc|cc}
\hline & Status & \multicolumn{3}{c}{ Annual eGFR decrease } \\
\hline HTN & DM & MA & eGFR < 60 & eGFR $\geq \mathbf{6 0}$ \\
\hline No & No & No & 0.65 & 0.65 \\
& & Yes & 4.2 & 0.72 \\
& Yes & No & 2.8 & 1.1 \\
& & Yes & 5.2 & 4.1 \\
Yes & No & No & 1.4 & 0.72 \\
& & Yes & 3.9 & 0.78 \\
& Yes & No & 2.8 & 1.1 \\
& & No & 5.2 & 4.1 \\
\hline
\end{tabular}

Table II. eGFR decrease according to clinical status (diabetes, hypertension and macroalbuminuria)

DM = Diabetes Mellitus; $\mathrm{HTN}=$ hypertension; $\mathrm{MA}=$ macroalbuminuria

- The reduction of eGFR due to clinical risk factors (diabetes, hypertension and macroalbuminuria incidence);

- The acceleration/deceleration in eGFR reduction due to HIV risk factors (HIV infection, HIV severity, ART).

\section{Initial renal function estimate}

According to Guidelines [19], CKD severity is classified into five stage depending on the eGFR value; kidney function is normal in stage 1 and minimally reduced in stage 2 (Table I).

The value of eGFR is calculated using different predictive models available in literature. All available equations (for adult population) are incorporated in the software and implemented in the models as starting points of the simulation of glomerular disease progression:

- Cockcroft-Gault formula [22]

$$
\begin{aligned}
\text { eGFR }= & (140-\text { Age }) \cdot W / 72 \cdot \text { Sc } . \\
& (0.85 \text { if female })
\end{aligned}
$$

where $\mathrm{W}$ is the real weight if $\mathrm{BMI}$ is normal (between 18.5 and 25) otherwise is calculat- ed as the ideal BMI (18.5 if BMI $<18.5$ and 25 if BMI > 25) multiplied by the square of height. Resulting value is then standardised to BSA equal to $1.73 \mathrm{~m}^{2}$.

- Modified Diet Renal Disease (MDRD) equation [23]

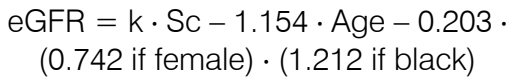

Where $\mathrm{k}$ is equal to 175 for standardized serum creatinine and 186 otherwise.

- CKD-EPI equation [24]

$$
\begin{gathered}
\mathrm{eGFR}=141 \cdot \min (\mathrm{Sc} / \mathrm{k}, 1)-\mathrm{a} \cdot \max (\mathrm{Sc} / \mathrm{k}, 1) \\
-1.209 \cdot 0.993 \mathrm{Age} \cdot(1.018 \text { if female }) \cdot \\
(1.159 \text { if black })
\end{gathered}
$$

Where $\mathrm{k}$ is 0.7 for females and 0.9 for males, a is 0.329 for females and 0.411 for males.

- Mayo Quadratic (MQ) formula [25]

$$
\begin{gathered}
\mathrm{eGFR}=\exp \left(1.911+5.249 / \mathrm{Sc}-2.114 / \mathrm{Sc}^{2}-\right. \\
0.00686 \cdot \text { Age }-(0.205 \text { if female }))
\end{gathered}
$$

The formula better estimates GFR in patients with preserved kidney function but it was not developed in a general population sample (elderly and African-American persons were underrepresented).

In all models, $\mathrm{Sc}$ is the serum creatinine value expressed in $\mathrm{mg} / \mathrm{dl}$, the age is measured in years and weight in $\mathrm{kg}$.

\section{eGFR decrease (without HIV influence)}

Annual eGFR decreases are based on a recent microsimulation model developed by Hoerger et al. [26]. The values are function of the initial value of eGFR, presence of diabetes and/or hypertension and evidence of persistent macroalbuminuria (defined as albumincreatinine ratio $\geq 300 \mathrm{mg} / \mathrm{g}$ ). Absolute annual reductions used in the model, expressed in $\mathrm{ml} / \mathrm{min} / 1.73 \mathrm{~m}^{2}$, are detailed in Table II. 


\section{HIV factor risks}

Five HIV-specific CKD risk factors were identified in the literature and incorporated in the model basing on the results of comparative studies:

- PLHIV versus HIV-uninfected people [14];

- Late-stage HIV infection versus nonAIDS PLHIV [14];

- ART versus treatment-naïve PLHIV [14];

- Nucleoside reverse transcriptase inhibitors (NRTIs) pair:

- specific for each drugs [6];

- including vs not including tenofovir [13].

- Third drug prescription [6].

Unfortunately the definition of renal disease is different in the studies: in Islam 2012 [14] and in Scherzer 2012 [13] renal disease is defined as eGFR $<60 \mathrm{ml} / \mathrm{min} / 1.73 \mathrm{~m}^{2}$ for greater than or equal to 3 months irrespective of kidney damage while in Tordato 2011 [6] it is defined as a confirmed $>20 \%$ eGFR reduction from baseline (Table III).

\section{eGFR progression algorithm during the baseline period}

The progression of renal disease in the first 3 years is evaluated according with the following algorithm:

1. The initial eGFR value is calculated according to patient characteristics;

2. Annual absolute eGFR reduction is determined according to clinical risk factors;

3. The absolute reduction is converted into an annual reduction rate $\left(\lambda_{\text {BASAL }}\right)$ supposing exponential decay in eGFR value;

4. Using this rate, the time $\left(\mathrm{T}_{\mathrm{CRIT}}\right)$ at which eGFR falls below $60 \mathrm{ml} / \mathrm{min} / 1.73 \mathrm{~m}^{2}$ is calculated;

5. $\mathrm{T}_{\mathrm{CRIT}}$ is corrected for HIV relative factors (excluding specific drugs influence);

6. A new annual reduction rate $\left(\lambda_{\text {CRIT }}\right)$ is calculated according to this corrected $\mathrm{T}_{\mathrm{CRIT}}$;

7. $\lambda_{\text {CRIT }}$ is corrected for specific third drug/ drug class as reported in section "HIV factor risk";

\begin{tabular}{|c|c|c|c|}
\hline CKD comparison & Outcome measures & $95 \% \mathrm{Cl}$ & p-value \\
\hline PLHIV vs. non-HIV (adjusted for sex, age and race) & RR: 3.87 & $2.18-6.85$ & \\
\hline Late stage HIV vs. non-AIDS PLHIV & RR: 3.32 & $1.86-5.93$ & \\
\hline ART vs. treatment-naïve & RR: 0.54 & 0.29-0.99 & \\
\hline \multicolumn{4}{|l|}{ NRTI pair [6] } \\
\hline - Zidovudine/lamivudine & $\mathrm{RR}: 1$ & & \\
\hline - Tenofovir/emtricitabine & RR: 4.78 & $2.19-10.43$ & $<0.001$ \\
\hline - Tenofovir/lamivudine & RR: 4.2 & $1.95-9.02$ & $<0.001$ \\
\hline - Abacavir/lamivudine & RR: 1.88 & $0.63-5.65$ & $\mathrm{NS}^{1}$ \\
\hline - Stavudine/lamivudine & RR: 2.06 & $0.26-16.34$ & $\mathrm{NS}^{1}$ \\
\hline - Didanosine/emtricitabine & RR: 11.88 & $2.27-62.18$ & $<0.01$ \\
\hline - Didanosine/lamivudine & RR: 1.81 & $0.38-8.59$ & $\mathrm{NS}^{1}$ \\
\hline - Didanosine/stavudine & RR: 2.54 & $0.31-20.46$ & $\mathrm{NS}^{1}$ \\
\hline - Other (single agent or $>2$ NRTIs) & RR: 0.43 & $0.07-2.55$ & $\mathrm{NS}^{1}$ \\
\hline \multicolumn{4}{|l|}{ TNF vs. no TNF including regimes [13] } \\
\hline - TNF exposure $<0.5$ years & HR: 1.30 & $0.91-1.86$ & $\mathrm{NS}^{2}$ \\
\hline - TNF exposure 0.5-1 years & HR: 1.85 & $1.35-2.53$ & $<0.001$ \\
\hline - TNF exposure 1-3 years & HR: 1.69 & $1.26-2.27$ & $<0.001$ \\
\hline - TNF exposure $>3$ years & HR: 1.56 & $0.73-3.36$ & $\mathrm{NS}^{2}$ \\
\hline \multicolumn{4}{|l|}{ Third drug/drug class } \\
\hline - NNRTI ${ }^{3}$ & RR: 1 & & \\
\hline - Non-indinavir single PI & RR: 3.18 & $1.62-6.23$ & $<0.001$ \\
\hline - Non-indinavir $\mathrm{Pl} / \mathrm{r}$ & RR: 2.15 & $1.25-3.70$ & $<0.01$ \\
\hline - NRTIs only & RR: 9.39 & $1.79-49.32$ & $<0.01$ \\
\hline
\end{tabular}

Table III - Relative risks related to HIV risk factors

$\mathrm{HR}=$ Hazard Ratio; PI = Protease Inhibitor; $/ \mathrm{r}=$ ritonavir-boosted; RR = Relative Risk; TNF = tenofovir

${ }^{1}$ Non significant RR was considered equal 1

${ }^{2}$ Association of tenofovir exposure with CKD risk for less than one year was not taken into account since the model allows only switch of therapy at the end of the year of simulation. After 3 years the effect of tenofovir was not considered differential

${ }^{3}$ Non NRTI 


\begin{tabular}{|c|c|c|c|c|}
\hline & \multicolumn{3}{|c|}{ Start eGFR $\left(\mathrm{ml} / \mathrm{min} / 1.73 \mathrm{~m}^{2}\right)$} & \multirow{2}{*}{ Overall } \\
\hline & $<60$ & $60-90$ & $>90$ & \\
\hline \multicolumn{5}{|c|}{ Tenofovir discontinuation } \\
\hline - $<3$ months & $23.8(8.5-39.0)$ & $15.8(10.0-21.6)$ & $9.5(4.7-14.3)$ & $12.5(8.9-16.1)$ \\
\hline - $>3$ months & $-0.4(-6.4-5.7)$ & $0.3(-0.8-1.4)$ & $1.2(0.12-2.1)$ & $0.8(0.1-1.5)$ \\
\hline Weighted slopes ${ }^{1}$ & 6.550 & 4.550 & 2.975 & \\
\hline
\end{tabular}

Table IV. eGFR slopes after tenofovir exposure

' eGFR slopes after tenofovir discontinuation ( $<3$ months) according to start eGFR value were mediated by the overall eGFR slope ( $>3$ months) since detailed slopes lacked statistical significance

The effect of the NRTI pair can be simulated according to two different data sets, Tordato 2011 [6] and Scherzer 2012 [13].

- Model 1 (based on Tordato 2011 [6]): According to the decay-rate related definition of renal disease in Tordato 2011

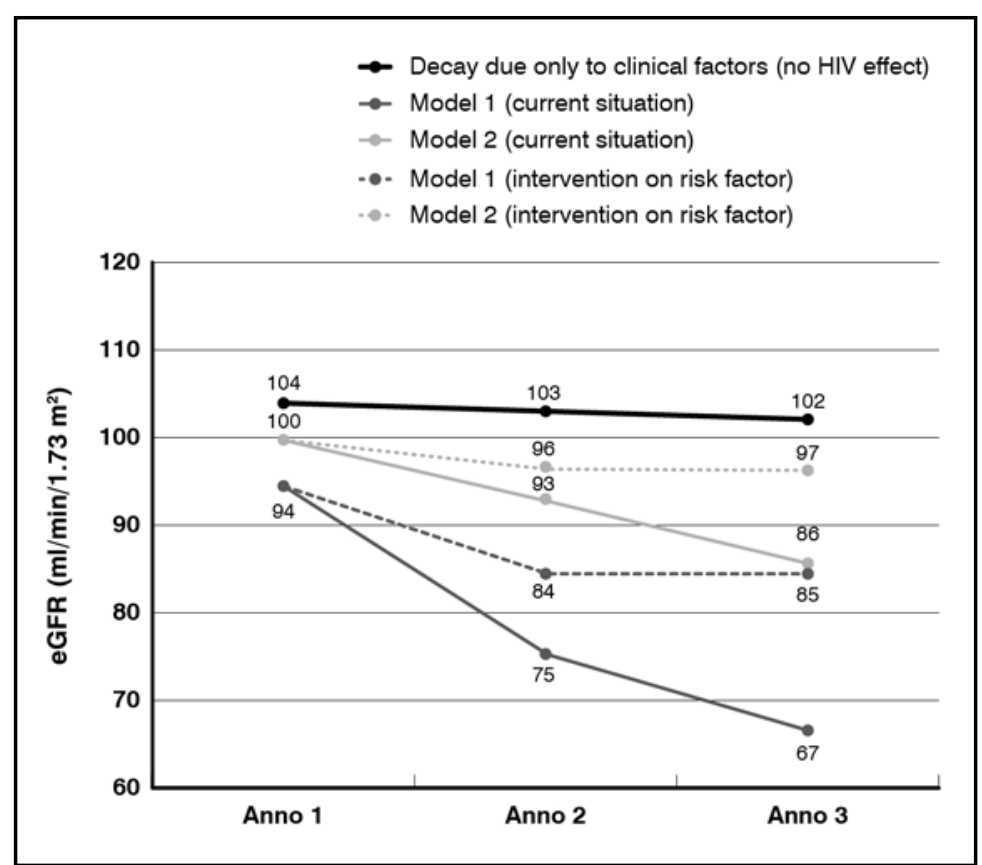

Figure 1. CKD progression according to simulation algorithm (during baseline period); the evolution according to the two models is compared with the effect of intervention on risk factor (confirmed $>20 \%$ eGFR reduction from baseline), NRTI pair-specific RRs are applied directly to $\lambda_{\text {CRIT }}$. The new rate is used to estimate eGFR progression (under the exponential hypothesis and applying half-cycle correction) only for the first two years of simulation, as for the third year of the baseline period we suppose no influence of specific ART regimen.

- Model 2 (based on Scherzer 2012 [13]): The influence of NRTI pair is modelled using HR reported in Scherzer 2012 (tenofovir vs no tenofovir) for all 3 years of the baseline period. The reported HR for eGFR $<60 \mathrm{ml} / \mathrm{min} / 1.73 \mathrm{~m}^{2}$ is directly applied to $\lambda_{\text {CRIT }}$ (similarly to model 1 ).

\section{INTERVENTION ON RISK FACTORS}

The model takes into account possible interventions on risk factors during the baseline period. Such HIV therapy related interventions can be applied at most within 3 years from the start of simulation. Furthermore it is also possible to consider the reversibility of eGFR trend due to tenofovir discontinuation (if tenofovir was included in the current treatment for at least 1 year), as reported in Jose 2014 [15] (Table IV).

\begin{tabular}{lccc}
\hline & $\begin{array}{c}\text { Current situation (\%) } \\
\text { [mean (IQR)] }\end{array}$ & $\begin{array}{c}\text { Alternative situation (\%) } \\
\text { [mean (IQR)] }\end{array}$ & $\begin{array}{c}\text { Risk reduction (\%) } \\
\text { [relative difference] }\end{array}$ \\
\hline Risk of ESRD post baseline & $0.023(0.0051-0.068)$ & $0.009(0.002-0.026)$ & $\mathbf{6 0 . 9}$ \\
- after 1 year & $0.13(0.029-0.38)$ & $0.05(0.011-0.15)$ & $\mathbf{6 1 . 5}$ \\
- after 3 years & $0.42(0.093-1.2)$ & $0.16(0.036-0.48)$ & $\mathbf{6 1 . 9}$ \\
- after 5 years & $1.5(0.33-4.3)$ & $0.58(0.13-1.7)$ & $\mathbf{6 1 . 3}$ \\
- after 10 years & & & $\mathbf{1 4 . 3}$ \\
Mortality post baseline & $0.77(0.45-1.5)$ & $0.66(0.38-1.3)$ & $\mathbf{1 4 . 8}$ \\
- after 1 year & $2.7(1.6-5.3)$ & $2.3(1.4-4.6)$ & $\mathbf{1 3 . 5}$ \\
- after 3 years & $5.2(3.1-10)$ & $4.5(2.6-8.8)$ & $\mathbf{7 . 1}$ \\
- after 5 years & $14(8.5-28)$ & $13(7.3-24)$ & \\
- after 10 years &
\end{tabular}

Table V. ESRD risk and mortality for the patient described in the example and effect of intervention on HIV risk factors 


\section{RISK OF ESRD AND MORTALITY}

The association eGFR decline with subsequent progression to ESRD and mortality is investigated in a recent paper by Coresh et al. [27]. An individual meta-analysis was conducted on 1.7 million participants with 12,344 ESRD events and 223,944 deaths from 35 cohorts in the CKD Prognosis Consortium.

ESRD is defined as initiation of renal replacement therapy or death due to kidney disease other than acute kidney injury; all-cause mortality are considered as well as cardiovascular (myocardial infarction, heart failure, stroke and sudden cardiac death) and non-cardiovascular mortality are also reported.

Results of the meta-analysis are presented in terms of absolute risk of ESRD or mortality at $1,3,5$, and 10 years after the baseline period as a function of the first value and the change of eGFR during a 2-year baseline period [27]. Such values are used in this model to estimate ESRD risk and mortality according to simulated progression of renal disease in a 3 -years baseline period.

\section{EXAMPLE}

Consider a white, male, 50 years old patient with a basal serum creatinine value of 0.8 $\mathrm{mg} / \mathrm{dl}$, with hypertension, no diabetes and no macroalbuminuria; he is in treatment for HIV infection (no AIDS) with tenofovir/emtricitabine as backbone and a PI as the third drug. Using CKD-EPI equation, initial eGFR results in $104 \mathrm{ml} / \mathrm{min} / 1,73 \mathrm{~m}^{2}$ with an absolute annual reduction of 0.72 that corresponds to 0.007 annual reduction rate $\left(\lambda_{\text {BASAL }}\right)$. The eGFR falls below $60 \mathrm{ml} / \mathrm{min} / 1,73 \mathrm{~m}^{2}$ after 80 years $\left(\mathrm{T}_{\mathrm{CRIT}}\right)$ reducing to 38 years after applying HIV specific relative risks. By requiring that the eGFR reaches the threshold of $60 \mathrm{ml} / \mathrm{min} / 1,73 \mathrm{~m}^{2}$ at $\mathrm{T}_{\text {CRIT }}$ we get $\lambda_{\text {CRIT }}$ equal to 0.014 .

The progression of eGFR during the baseline with these settings (current situation), according to different models, is shown in Figure 1 (continuous lines). If after the first year, patient switch from the current therapy to abacavir/lamivudine + NNRTI, the decreasing in eGFR reduces (Figure 1 - dotted lines). As reference value, the evolution of the same patient without HIV was considered applying only the annual decrease expected due to clinical risk factors.

In the current situation, the mean eGFR during the first year of baseline period is $94 \mathrm{ml} /$ $\min / 1.73 \mathrm{~m}^{2}$ with a reduction in 3 years of $36.0 \%$ and $17.6 \%$, according to predictions by model 1 model 2, respectively. After 10 years, the risk of ESRD results in $1.5 \%$ (IQR: 0.33 $4.3 \%$ ) and mortality in $14 \%$ (IQR: $8.5-28 \%$ ) for both models. The intervention on HIV

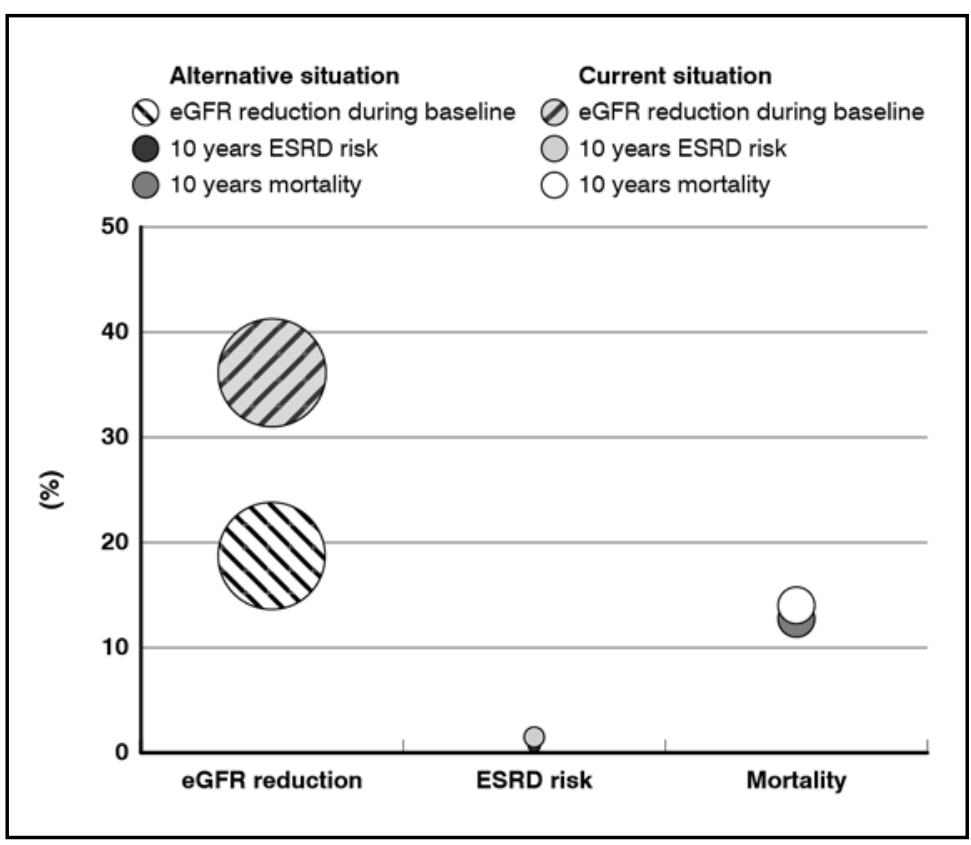

Figure 2. Bubble-plot shows, in order, relative reduction of eGFR in baseline period, 10 years ESRD risk and mortality according to model 1 (bubble size of eGFR reduction represents mean eGFR during first year of simulation while the sizes of ESRD risk and mortality bubbles are proportional to the probability not to exceed the predicted mean values)

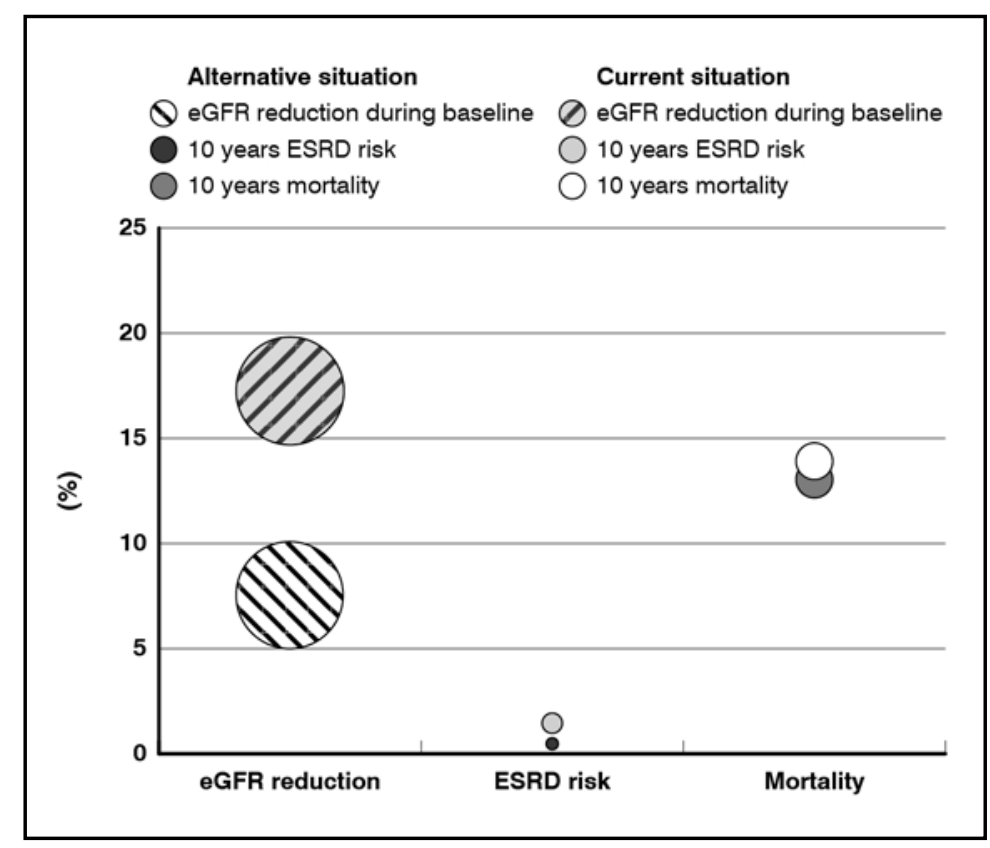

Figure 3. Bubble-plot shows, in order, relative reduction of eGFR in baseline period, 10 years ESRD risk and mortality according to model 2 (bubble size of eGFR reduction represents mean eGFR during first year of simulation while the sizes of ESRD risk and mortality bubbles are proportional to the probability to not exceed the predicted mean values)

risk factors leads to a slowdown in the decay of eGFR: reduction in the first three years is in fact equal to $18.6 \%$ for model 1 and $7.3 \%$ for model 2 (Figure 2 and Figure 3). The new trend in eGFR results in a reduction of over $60 \%$ in the risk of ESRD and $7 \%$ in mortality. Results for 1, 3, 5 and 10 years after the end of baseline period are reported in Table V. 


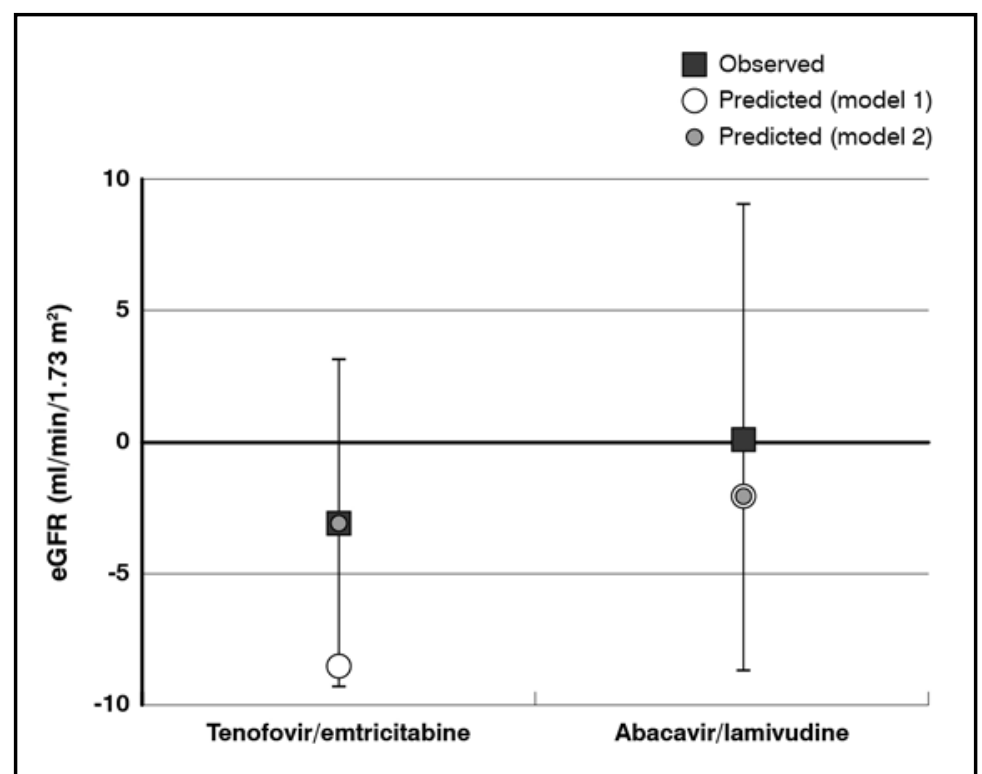

Figure 4. Annual variation in eGFR: comparison between Maggi 2011 and simulation results analysis but not used in the final formulation of the models. These external validations compare data observed in the studies with model predictions obtained simulating the experience of a cohort with the same distribution of risk factors of the patients enrolled in the study; unfortunately, the overlapping among risk factors is not reported in detail in any of such studies, but it had to be inferred from epidemiological data. Furthermore, no study was identified that reported all evaluated outcomes on the same population, so we tested the components of the overall model separately: predicted evolution of EGFR values has been compared (Figure 4) to data reported by Maggi in 2012 [29], while the effect of EGFR declining in a baseline period on risk of ESRD and mortality (Figure 5) was compared with data observed in [30-33], which were clinical studies conducted on a non-HIV population. Overall, the models' predictions compare reasonably well with observed data: if EGFR decrease appears to be slightly overestimated, in particular by model 2 (ICONA-cohort based risks), this is offset by an opposite modest underestimation of subsequent hard end-points incidence. 


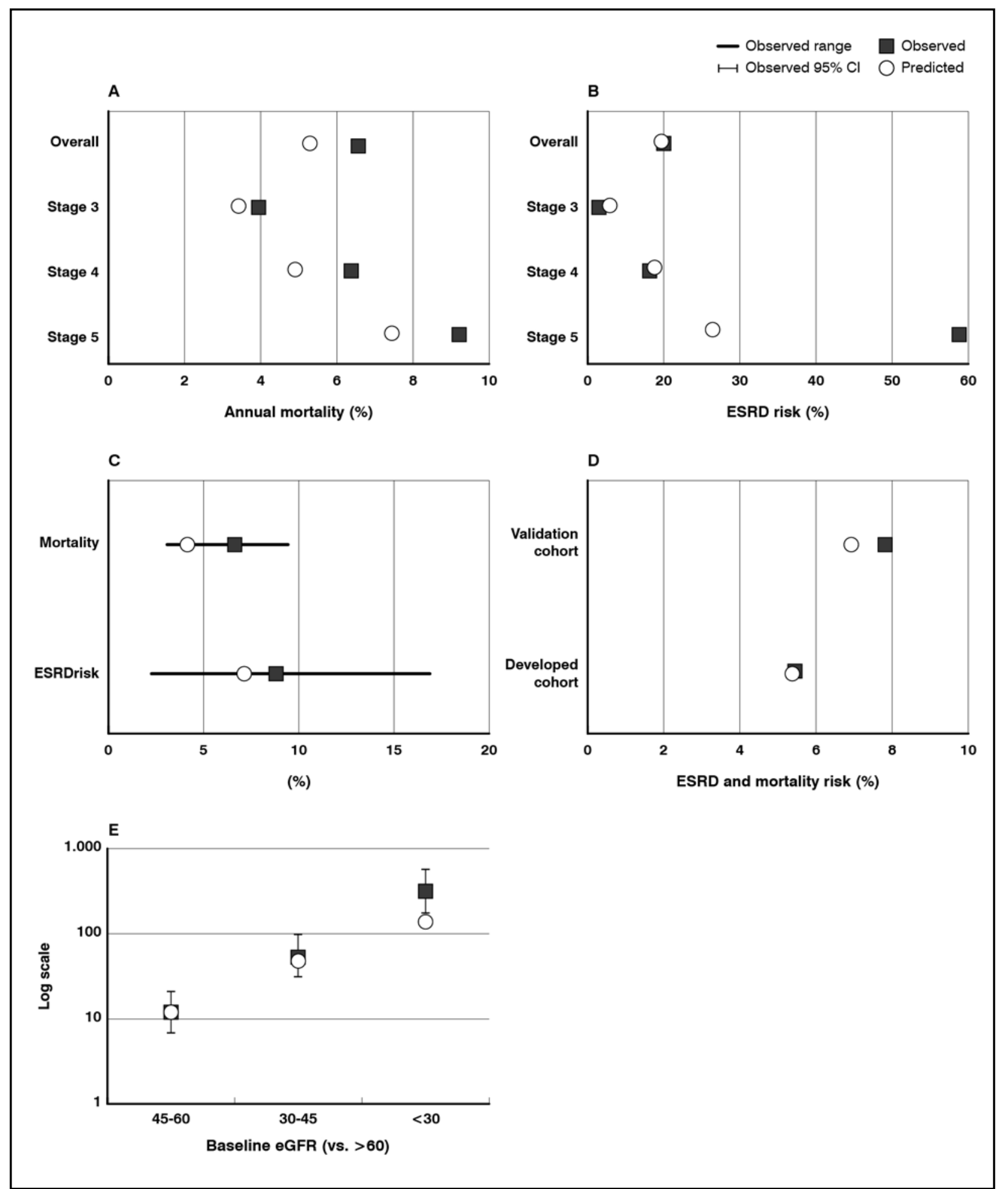

Figure 5. Comparison between simulation results and annual mortality (all-cause mortality) in Landray 2010 [30] (panel A), ESRD risk in Landray 2010 [30] (panel B), ESRD risk and mortality in Desai 2011 [31] (panel C) and in Tangri 2011 [32] (panel D), and risk factor associated with ESRD in Hallan 2009 [33] (panel E - Log scale) 



\section{Osteopathy model}

\section{BACKGROUND - FRACTURE RISK IN PLHIV}

Bone strength is the result of bone mineral density (BMD) and bone microarchitecture. A decrease in BMD leads to deterioration of microarchitecture, leading to critical damage and porosity that weaken bone and increase the probability of fractures [34].

A case-finding approach for a pharmacological treatment appears to be obligatory, at least with the available drugs. In Italy this problem has been approached by the health authorities by granting drug reimbursement only for patients with a higher risk of fracture [35].

In the last years, it has become commonly accepted the notion that the risk of fracture does not depend exclusively by the BMD, but that many other clinical risk factors (CRFs) contribute to influence it. For this reason, Italian NHS identifies the patient to be taken "in charge" based on various CRFs, like fractures history, steroid chronic treatment, smoking, in addition to BMD.

Many instruments have been developed to predict fracture risk, especially in postmenopausal women; among these, FRAX ${ }^{\circledR}$, with the WHO support, is the most used, estimating 10-years hip or other major osteoporotic fractures (clinical spine, forearm, hip or shoulder fracture) probability. The algorithm has been developed from studying population-based cohorts from Europe, North America, Asia and Australia.

In Italy, as done in other countries, a national version of this model, called DeFRA, has been implemented in order to use it for regulatory scopes.

Despite HIV infection is one of the most recently identified factor that leads to accelerated bone loss, with up to $25 \%$ of HIV-infected patients fulfilling osteoporosis criteria and up to $50 \%$ those for osteopenia [36-38], both the national and the original versions of the algorithm do not include it among CRF.

The high morbidity, mortality and management cost associated to bone fractures [39] make optimal monitoring and appropriate treatment essential, especially for patients at high risk, such as the HIV-infected population.
The present model has been planned to evaluate fracture risk in HIV-infected patients, based on the probability rate estimated by DeFRA adjusted for the HIV condition and for the administration of antiretroviral drugs with a well-known musculoskeletal toxicity. Furthermore, the desired model had to be able to predict the temporal evolution of the risk, taking into account the impact of possible interventions on modifiable CRFs.

\section{FRACTURE RISK EVALUATION}

\section{HIV-free fracture risk}

The 10-year risk (10 YR) of multiple major fractures is calculated using DeFRA algorithm:

$$
\begin{gathered}
\text { logit (10YR) }=a_{1} \text { Age }+a_{2} \text { Age }^{2}+ \\
a_{3} \text { Age }^{3}+a_{4} \text { BMI }+a_{5} B M l^{2}+a_{6} T+a_{7} T^{2}+ \\
\left(a_{8} \text { Age }+a_{9} \text { BMI }\right) T+\text { const }
\end{gathered}
$$

where age is expressed in years, BMI is the body mass index and $\mathrm{T}$ is the T-score. Coefficients of equation are reported in Table VI. Hip fracture incidence accounts for 13-33\% of all non-vertebral fractures in the placebo arm of the largest RCTs focus on osteoporotic treatment [40-44]. According to a recent cost-effectiveness analysis performed by Adami et al. [45] we assume a proportion of hip

\begin{tabular}{cc}
\hline Coefficients & Multiple clinical fractures \\
\hline$a_{1}$ & -0.54072 \\
$a_{2}$ & 0.00875 \\
$a_{3}$ & -0.00004 \\
$a_{4}$ & 0.08077 \\
$a_{5}$ & -0.00145 \\
$a_{6}$ & -0.00654 \\
$a_{7}$ & 0.08938 \\
$a_{8}$ & -0.00148 \\
$a_{9}$ & -0.00102 \\
const & 5.98739 \\
\hline
\end{tabular}

Table VI. Coefficients of DeFRA algorithm equations 


\begin{tabular}{|c|c|c|}
\hline \multirow[b]{2}{*}{ Clinical risk factor } & \multicolumn{2}{|c|}{ DeFRA risk gradients } \\
\hline & Hip fracture & $\begin{array}{l}\text { Multiple clinical } \\
\text { fractures }\end{array}$ \\
\hline Family history of hip fracture & 1.6 & 1.2 \\
\hline \multicolumn{3}{|l|}{ Corticosteroid use ${ }^{1}$} \\
\hline - $>5$ mg prednisone equivalents & 2.5 & 2.5 \\
\hline - $2.5-5 \mathrm{mg}$ prednisone equivalents & 1.8 & 1.6 \\
\hline \multicolumn{3}{|l|}{ Previous vertebral o hip fracture ${ }^{2}$} \\
\hline - One & 2.2 & 2.2 \\
\hline - More than one & 4.0 & 4.0 \\
\hline $\begin{array}{l}\text { Previous non-traumatic non-hip } \\
\text { non-vertebral fracture }{ }^{2}\end{array}$ & 1.4 & 1.4 \\
\hline Alcohol (> 3 units $/$ day $)^{3}$ & 1.5 & 1.2 \\
\hline \multicolumn{3}{|l|}{ Smoking ${ }^{4}$} \\
\hline - $<10$ cigarettes /day & 1.2 & 1.0 \\
\hline - $>10$ cigarettes /day & 1.9 & 1.5 \\
\hline $\begin{array}{l}\text { Rheumatoid and psoriatic arthritis, } \\
\text { ankylosing spondyloarthritis, any } \\
\text { connective tissue disease }\end{array}$ & 1.3 & 1.2 \\
\hline
\end{tabular}

Table VII. Gradients associated with each clinical risk factor (CRF) for the DeFRA project

Applicable to patients on corticosteroid therapy for more than 3 months. Prior treatment courses are not considered.

${ }^{2} \mathrm{~A}$ fragility fracture is a fracture sustained after falling from a height not exceeding the body height or occurring after minimal or no trauma. Morphometric (even asymptomatic) moderate or severe (Genant- method) vertebral fractures are also included.

${ }^{3}$ Currently drinking 3 or more units of alcohol. A unit of alcohol is defined as a $285 \mathrm{ml}$ glass of beer, a $120 \mathrm{ml}$ glass of wine, a $60 \mathrm{ml}$ measure of aperitif, or a $30 \mathrm{ml}$ measure of spirit.

${ }^{4}$ Current smoking only: previous smoking is not considered.

fracture of $20 \%$ corresponding to moderate to severe risk patients.

Once applied relative risks associated with CFRs, annual fracture rates are obtained from 10-year risks supposing an exponential growth trend of the risk.

\section{Clinical risk factors}

After the age of 40 , the history of a previous fracture is one of the strongest CRF for new incident fractures [46-53]. The mean $\mathrm{RR}$ is 2.2 , but the value depends on age and on the site and number of previous fractures $[47,52,54]$.

A parenteral history of hip fracture is associated with a significant risk both of all osteoporotic fractures and of hip fracture; the

\begin{tabular}{lcc}
\hline \multirow{2}{*}{ HIV risk factor } & \multicolumn{2}{c}{ Hazard Ratio (HR) } \\
\cline { 2 - 3 } & Male & Female \\
\hline HIV infection & 1.10 & 1.00 \\
TDF & 1.11 & 1.11 \\
PI & 1.10 & 1.10 \\
TDF+PI & 1.16 & 1.16 \\
\hline
\end{tabular}

Table VIII. Influence of HIV infection and HAART therapy on annual osteoporotic fracture risk risk results independent of BMD [55]. Also a family history of any fracture in parents was associated with a modest but significantly increased risk of any osteoporotic fracture and of hip fracture [55].

Smoking is a risk factor in particular for hip fractures, in part due to its negative effects on BMD and BMI. Smoking increases fracture risk even independently of age, BMD and BMI [56]. The relative risk depends considerably on the number of cigarettes per day and it decreases with time since smoking cessation [57].

Alcoholism is widely considered as a CRF for osteoporotic fractures and low bone density, with effects varying in a non-linear way according to intake [58]. Generally no significant increase in risk is observed at daily intakes of less than 3 units while above this threshold, alcohol intake is associated with an increased risk factor both of hip and multiple fractures $[59,60]$.

One of the most serious complications of corticosteroids is osteoporosis and an increased fracture risk. The increased risk is more strongly related to daily dose than to the cumulative dose with a monotonic relationship [48]. Several early studies documented an increased fracture risk in subjects with rheumatoid [61-63] and psoriatic arthritis [64], ankylosing spondyloarthritis [65-66] and in general with any connective tissue disease.

Relative risks associated with each CRF described above and used in the model are reported in Table VII.

\section{HIV risk factors}

The association between HIV infection and increased risk of fragility fracture was explored by Womack et al. by Cox regression models in male Veterans enrolled in the Veterans Aging Cohort Study Virtual [67]. After adjusting for demographics, comorbid disease, smoking, alcohol abuse and BMI, HIV infection results associated with a trend towards an increased fracture risk (HR: 1.10; 95\% CI: 0.97-1.25).

Specific analyses carried out on female samples [68-69] revealed no excess risk in patients infected, so in the model no risk factor for women was introduced.

While HIV infection itself has adverse skeletal effects, the introduction of HAART may also contribute to accelerated bone loss [70]. Previous studies have suggested that ARVs drugs differ in their impact on bone health: tenofovir (TDF) has been found to be associated with a greater decline in BMD than stavudine [71] or abacavir [72]. Also, earlier studies had suggested that exposure to protease inhibitors (PIs) decreased BMD [73], 
and it has been recently suggested that atazanavir is associated with increased risk of osteoporosis, compared to efavirenz [72]. Finally, antiretroviral initiation has been shown to be associated with a rapid and significant increase in levels of serologic markers of increased bone turnover (which might signify increased bone fragility) [74-76].

The work of Bedimo et al. [77] was indicated by the expert panel as the most complete and consistent source, since it evaluated the effect of cumulative exposure to both TDF and PI. Four different exposure categories were selected:

- Exposure to neither TDF nor PI (referent category);

- Exposure to TDF, but not PI;

- Exposure to PI, but not TDF;

- Concomitant exposure to TDF and PI.

Concomitant exposure to both TDF and PI associated with a greater osteoporotic fracture risk (HR: 1.16; 95\% CI: 1.04-1.30) than exposure to either TDF without PI (HR: 1.11; 95\% CI: 1.01-1.21) or PI without TDF (HR: 1.10; 95\% CI: 1.01-1.22).

All values applied to annual fracture rates in the model are summarized in Table VIII.

\section{Complex fracture risk}

By averaging the fracture incidence ratios observed in the most important pivotal trials it is apparent that approximately $25 \%$ of major fractures are identified vertebral fractures, which comprise $33 \%$ of all vertebral fractures [45]. Major clinical fractures are on average made up of $25 \%$ vertebral fractures, $20 \%$ hip fractures and $55 \%$ other non-vertebral fractures.

Complex fracture risk (including non-clinical vertebral fracture) thus results in the sum of clinical fracture risk and twice clinical vertebral fracture risk.

\section{EXAMPLE}

Baseline patient characteristics and clinical/ HIV risk factors are reported in Table IX.

The current situation is compared with two interventions:

1. A first intervention on lifestyle (no alcohol and no smoking);

2. A second intervention on ART therapy (tenofovir and $\mathrm{PI} / \mathrm{r}$ discontinuation).

Resulting fracture risks are reported in Table X.

\section{MODEL VALIDATION}

As for the nephropathy model, also for the prediction of fracture risk, a series of validations are performed using studies not used in

\begin{tabular}{|c|c|}
\hline \multirow[t]{3}{*}{ Baseline value } & - Age: 40 years \\
\hline & • BMI: 22.86 \\
\hline & - T-score: -1 \\
\hline \multirow[t]{5}{*}{ Clinical risk factors } & - No family history of hip fracture \\
\hline & - Corticosteroid use $>5 \mathrm{mg}$ \\
\hline & - None previous fracture \\
\hline & - Alcohol (>3 units /day) \\
\hline & - Smoking <10 cigarettes /day \\
\hline \multirow[t]{2}{*}{ HIV risk factors } & - Tenofovir/emtricitabine \\
\hline & - Atazanavir/r \\
\hline
\end{tabular}

Table IX. Patient characteristics

\begin{tabular}{lcccc}
\hline & \multicolumn{4}{c}{ Fracture risk (\%) } \\
\cline { 2 - 5 } & Year 1 & Year 3 & Year 5 & Year 10 \\
\hline Current scenario & 0.8 & 2.3 & 3.8 & 7.5 \\
- Hip fracture & 2.4 & 7.0 & 11.3 & 21.4 \\
- Major clinical fracture & & & & \\
First intervention & 0.3 & 0.8 & 1.3 & 2.6 \\
- Hip fracture & 1.3 & 3.8 & 6.2 & 12.0 \\
- Major clinical fracture & & & & \\
Second intervention & 0.2 & 0.7 & 1.1 & 2.3 \\
- Hip fracture & 1.1 & 3.3 & 5.4 & 10.5 \\
\hline - Major clinical fracture & & & & \\
\hline
\end{tabular}

Table X. Estimated fracture risk in current and modified scenarios

the final formulation of the model. These external validations compare data observed in the studies with model predictions obtained simulating the experience of a cohort with the same distribution of risk factors of the

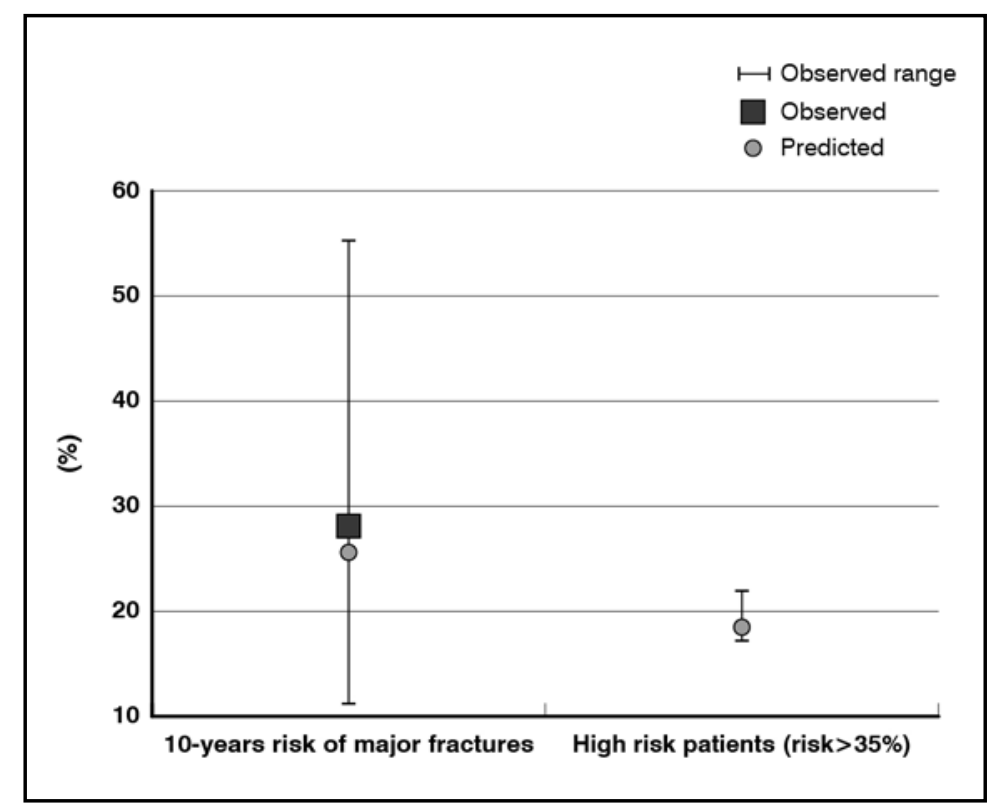

Figure 6. Comparison between simulation results and 10-years risk of fracture in Johansson 2004 [78] 


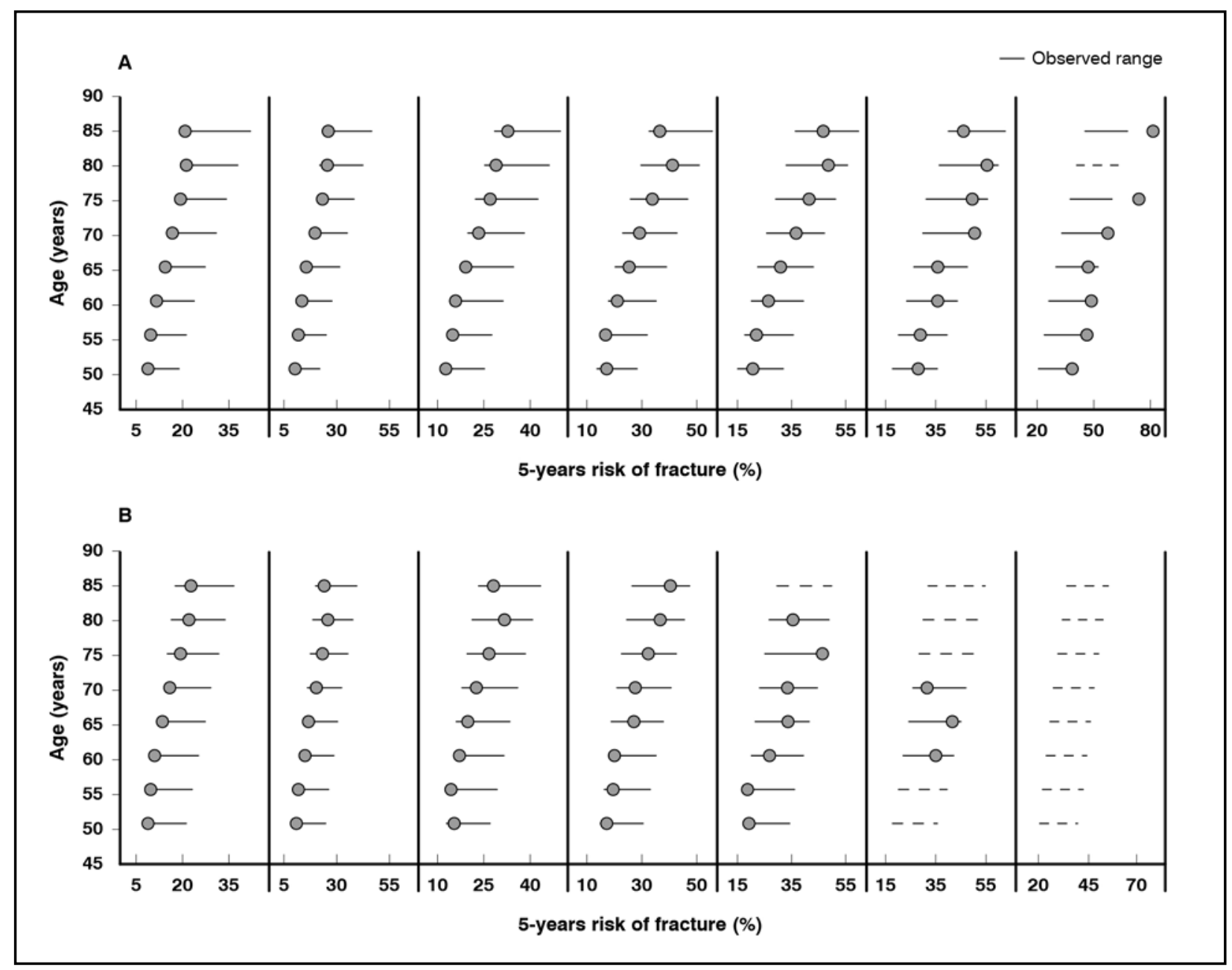

Figure 7. Comparison between simulation results and 5-years risk of fracture based on age and femoral T-score in women (panel A) and in men in Krege 2013 [79]

patients enrolled in the study; unfortunately, the overlapping among risk factors is not reported in detail in any of such studies, but it had to be inferred from epidemiological data and clinical knowledge.

The Figure 6 and Figure 7 report and compare the results of such simulated trials with the results reported in the papers. Again, the cohort- and subgroup-level predictions compare reasonably well with the observed data, although some underestimation in the fracture risk is detected when comparing with Johansson 2004 [78] and the low risk subgroups in Kraege 2013 [79], while the opposite (slight overestimation) is observed for the high-risk subgroups in the latter study. In any case, all predictions fall within the reported confidence intervals. 


\section{Discussion and conclusions}

HAART changed the natural history of HIV infection, transforming it in a chronic disease. In common with other chronic disease, the life-long exposure to therapeutic regimens is associated with an increased risk of secondary co-morbidities. We feel that the current perceptions of this risk increase, and the corresponding managing skills of treating physicians, are far from being optimal, and therefore aimed at developing a practical tool that could aid them to assess these risks and the potential of interventions to modulate them.

Concentrating on renal function and fracture risk, we reviewed the available literature and propose two disease progression models build upon the most reliable sources, as assessed by confrontation with infectivologists and expert clinicians in the respective fields. HIV-specific risk factors identified through this process (Infection itself, AIDS, and components of HAART) were integrated with published risk prediction models to establish these proposed models.

Some cohort-level validation runs performed by simulating clinical trials providing both the needed input data and outcome indicators show that the presented models are able to reproduce average results with acceptable accuracy. For a rigorous and formal testing of the predictive capability of the models, however, the predictions should be compared at the individual level on a large clinical database: this type of analysis is planned in the near future.

Nevertheless, given the practical aim of the tools, we believe that their capability of correctly indicating the expected course of the disease, and to be sensitive to the interplay of concomitant risk factors, is reassuring in regard to their intended use: providing a rational, credible and easily usable aid for a more informed decision-making process in HAART prescribing.

Furthermore, the ability of the present models to reliably predict hard outcomes at the cohort level render them suitable to be included in pharmacoeconomic simulation models developed for the comparative assessment of the economical consequences of different prescribing strategies that expand their focus beyond pharmaceutical acquisition costs, taking into the right consideration other items of healthcare resource consumption, in particular those needed for monitoring and managing the comorbidities of HIV in the HAART era. 



\section{References}

1. Joint United Nations Programme on HIV/AIDS (UNAIDS). Global report: UNAIDS report on the global AIDS epidemic. Geneva: UNAIDS, 2013

2. Antiretroviral Therapy Cohort Collaboration. Life expectancy of individuals on combination antiretroviral therapy in high-income countries: a collaborative analysis of 14 cohort studies. Lancet 2008; 372: 293-9; http://dx.doi.org/10.1016/S0140-6736(08)61113-7

3. Ross MJ, Klotman PE. Recent progress in HIV-associated nephropathy. J Am Soc Nephrol 2002; 13: 2997-3004; http://dx.doi.org/10.1097/01.ASN.0000040750.40907.99

4. Abbott KC, Hypolite I, Welch PG, et al. J Human immunodeficiency virus/acquired immunodeficiency syndrome-associated nephropathy at end-stage renal disease in the United States: patient characteristics and survival in the pre highly active antiretroviral therapy era. J Nephrol 2001; 14: 377-83

5. Mallipattu SK, Wyatt CM, He JC. The New Epidemiology of HIVRelated Kidney Disease. $J$ AIDS Clin Res 2012; Suppl 4: 001

6. Tordato F, Cozzi Lepri A, Cicconi P, et al.; ICONA Foundation Study Group. Evaluation of glomerular filtration rate in HIV-1-infected patients before and after combined antiretroviral therapy exposure. HIV Med 2011; 12: 4-13; http://dx.doi.org/10.1111/j.14681293.2010.00855.x.

7. Ryom L, Mocroft A, Kirk O, et al.; D:A:D Study Group. Association between antiretroviral exposure and renal impairment among HIV-positive persons with normal baseline renal function: the D:A:D study. J Infect Dis 2013; 207: 1359-69; http://dx.doi.org/10.1093/ infdis/jit043

8. Mocroft A, Kirk O, Reiss P, et al.; EuroSIDA Study Group. Estimated glomerular filtration rate, chronic kidney disease and antiretroviral drug use in HIV-positive patients. AIDS 2010; 24: 1667-78; http://dx.doi.org/10.1097/QAD.0b013e328339fe53

9. Hammer SM, Saag MS, Schechter M, et al.; International AIDS Society--USA Panel. Treatment for adult HIV infection: 2006 recommendations of the International AIDS Society-USA panel. JAMA 2006; 296: 827-43; http://dx.doi.org/10.1001/jama.296.7.827

10. Gallant JE, DeJesus E, Arribas JR, et al.; Study 934 Group. Tenofovir DF, emtricitabine, and efavirenz vs. zidovudine, lamivudine, and efavirenz for HIV. N Engl J Med 2006; 354: 251-60; http://dx.doi.org/10.1056/NEJMoa051871

11. Saag MS, Cahn P, Raffi F, et al.; FTC-301A Study Team. Efficacy and safety of emtricitabine vs stavudine in combination therapy in antiretroviral-naive patients: a randomized trial. JAMA 2004; 292: 180-9; http://dx.doi.org/10.1001/jama.292.2.180

12. Gallant JE, Parish MA, Keruly JC, et al. Changes in renal function associated with tenofovir disoproxil fumarate treatment, compared with nucleoside reverse-transcriptase inhibitor treatment. Clin Infect Dis 2005; 40: 1194-8; http://dx.doi.org/10.1086/428840

13. Scherzer R, Estrella M, Li Y, et al. Association of tenofovir exposure with kidney disease risk in HIV infection. AIDS 2012; 26: 867-75; http://dx.doi.org/10.1097/QAD.0b013e328351f68f

14. Islam FM, Wu J, Jansson J, et al. Relative risk of renal disease among people living with HIV: a systematic review and meta-analysis. BMC Public Health 2012; 12: 234; http:// dx.doi.org/10.1186/1471-2458-12-234

15. Jose S, Hamzah L, Campbell LJ, et al.; UK Collaborative HIV Cohort Study Steering Committee. Incomplete reversibility of estimated glomerular filtration rate decline following tenofovir disoproxil fumarate exposure. J Infect Dis 2014;210: 363-73; http://dx.doi.org/10.1093/infdis/jiu107 
16. Ryom L, Mocroft A, Kirk O, et al. Predictors of advanced chronic kidney disease and end-stage renal disease in HIV-positive persons. AIDS 2014; 28: 187-99; http://dx.doi. org/10.1097/QAD.0000000000000042

17. Laprise C, Baril JG, Dufresne S, et al. Association between tenofovir exposure and reduced kidney function in a cohort of HIV-positive patients: results from 10 years of follow-up. Clin Infect Dis 2013; 56: 567-75; http://dx.doi.org/10.1093/cid/cis937

18. Khan S, Amedia CA Jr. Economic burden of chronic kidney disease. J Eval Clin Pract 2008; 14: 422-34; http://dx.doi.org/10.1111/j.1365-2753.2007.00883.x

19. Levey AS, Coresh J. Chronic kidney disease. Lancet 2012; 379: 165-80; http://dx.doi. org/10.1016/S0140-6736(11)60178-5

20. Echouffo-Tcheugui JB, Kengne AP. Risk models to predict chronic kidney disease and its progression: a systematic review. PLoS Med 2012; 9: e1001344; http://dx.doi.org/10.1371/ journal.pmed.1001344

21. Ando M, Yanagisawa N, Ajisawa A, et al. A simple model for predicting incidence of chronic kidney disease in HIV-infected patients. Clin Exp Nephrol 2011; 15: 242-7; http://dx.doi. org/10.1007/s10157-010-0393-x

22. Cockcroft DW, Gault MH. Prediction of creatinine clearance from serum creatinine. Nephron 1976; 16: 31-41; http://dx.doi.org/10.7326/0003-4819-150-9-200905050-00006

23. Levey AS, Bosch JP, Lewis JB, et al. A more accurate method to estimate glomerular filtration rate from serum creatinine: a new prediction equation. Modification of Diet in Renal Disease Study Group. Ann Intern Med 1999; 130: 461-70

24. Levey AS, Stevens LA, Schmid CH, et al.; CKD-EPI (Chronic Kidney Disease Epidemiology Collaboration). A new equation to estimate glomerular filtration rate. Ann Intern Med 2009; 150: 604-12; http://dx.doi.org/10.7326/0003-4819-150-9-200905050-00006

25. Rule AD, Larson TS, Bergstralh EJ, et al. Using serum creatinine to estimate glomerular filtration rate: accuracy in good health and in chronic kidney disease. Ann Intern Med 2004; 141: 929-37; http://dx.doi.org/10.7326/0003-4819-141-12-200412210-00009

26. Hoerger TJ, Wittenborn JS, Segel JE, et al.; Centers for Disease Control and Prevention CKD Initiative. A health policy model of CKD: 1. Model construction, assumptions, and validation of health consequences. Am J Kidney Dis 2010; 55: 452-62; http://dx.doi. org/10.1053/j.ajkd.2009.11.016

27. Coresh J, Turin TC, Matsushita K, et al.; CKD Prognosis Consortium. Decline in estimated glomerular filtration rate and subsequent risk of end-stage renal disease and mortality. JAMA 2014; 311: 2518-31

28. Cohen MS, Chen YQ, McCauley M, et al.; HPTN 052 Study Team. Prevention of HIV-1 infection with early antiretroviral therapy. N Engl J Med 2011; 365: 493-505; http://dx.doi. org/10.1056/NEJMoa1105243

29. Maggi P, Montinaro V, Bellacosa C, et al. Early markers of tubular dysfunction in antiretroviral-experienced HIV-infected patients treated with tenofovir versus abacavir. AIDS Patient Care STDS 2012; 26: 5-11; http://dx.doi.org/10.1089/apc.2011.0185

30. Landray MJ, Emberson JR, Blackwell L, et al. Prediction of ESRD and Death Among People With CKD: The Chronic Renal Impairment in Birmingham (CRIB) Prospective Cohort Study. Am J Kidney Dis 2010; 56: 1082-94; http://dx.doi.org/10.1053/j.ajkd.2010.07.016

31. Desai AS, Toto R, Jarolim P, et al. Association between cardiac biomarkers and the development of ESRD in patients with type 2 diabetes mellitus, anemia, and CKD. Am J Kidney Dis 2011; 58: 717-28; http://dx.doi.org/10.1053/j.ajkd.2011.05.020

32. Tangri N, Stevens LA, Griffith J, et al. A predictive model for progression of chronic kidney disease to kidney failure. JAMA 2011; 305: 1553-9; http://dx.doi.org/10.1001/jama.2011.451

33. Hallan SI, Ritz E, Lydersen S, et al. Combining GFR and albuminuria to classify CKD improves prediction of ESRD. J Am Soc Nephrol 2009; 20: 1069-77; http://dx.doi.org/10.1681/ ASN.2008070730

34. NIH Consensus Development Panel on Osteoporosis Prevention, Diagnosis, and Therapy. 
Osteoporosis prevention, diagnosis, and therapy. JAMA 2001; 285: 785-95

35. Adami S, Bianchi G, Brandi ML, et al. Validation and further development of the WHO 10-year fracture risk assessment tool in Italian postmenopausal women: project rationale and description. Clin Exp Rheumatol 2010; 28: 561-70

36. Bonjoch A, Figueras M, Estany C, et al. High prevalence of and progression to low bone mineral density in HIV-infected patients: a longitudinal cohort study. AIDS 2010; 24: 2827 33; http://dx.doi.org/10.1097/QAD.0b013e328340a28d

37. Brown TT, Qaqish RB. Antiretroviral therapy and the prevalence of osteopenia and osteoporosis: a meta-analytic review. AIDS 2006; 20: 2165-74; http://dx.doi.org/10.1097/ QAD.0b013e32801022eb

38. Bruera D, Luna N, David DO, et al. Decreased bone mineral density in HIV-infected patients is independent of antiretroviral therapy. AIDS 2003; 17: 1917-23; http://dx.doi. org/10.1097/00002030-200309050-00010

39. Trombetti A, Herrmann F, Hoffmeyer P, et al. Survival and potential years of life lost after hip fracture in men and agematched women. Osteoporos Int 2002; 13: 731-7; http://dx.doi. org/10.1007/s001980200100

40. Black DM, Cummings SR, Karpf DB, et al. Randomised trial of effect of alendronate on risk of fracture in women with existing vertebral fractures. Fracture Intervention Trial Research Group. Lancet 1996; 348: 1535-41; http://dx.doi.org/10.1016/S0140-6736(96)07088-2

41. Cummings SR, Black DM, Thompson DE, et al. Effect of alendronate on risk of fracture in women with low bone density but without vertebral fractures: results from the Fracture Intervention Trial. JAMA 1998; 280: 2077-82; http://dx.doi.org/10.1001/jama.280.24.2077

42. Reginster JY, Seeman E, De Vernejoul MC, et al. Strontium ranelate reduces the risk of nonvertebral fractures in postmenopausal women with osteoporosis: treatment of Peripheral Osteoporosis (TROPOS) study. J Clin Endocrinol Metab 2005; 90: 2816-22; http://dx.doi. org/10.1210/jc.2004-1774

43. Black DM, Delmas PD, Eastell R, et al. Once-yearly zoledronic acid for treatment of postmenopausal osteoporosis. N Engl JMed 2007; 356: 1809-22; http://dx.doi.org/10.1056/ NEJMoa067312

44. McClung MR, Geusens P, Miller PD, et al.; Hip Intervention Program Study Group. Effect of risedronate on the risk of hip fracture in elderly women. N Engl J Med 2001; 344: 33340; http://dx.doi.org/10.1056/NEJM200102013440503

45. Adami S, Bertoldo F, Gatti D, et al. Treatment thresholds for osteoporosis and reimbursability criteria: perspectives associated with fracture risk-assessment tools. Calcif Tissue Int 2013; 93: 195-200; http://dx.doi.org/10.1007/s00223-013-9748-0

46. Black DM, Arden NK, Palarmo L, et al. Prevalent vertebral deformities predict hip fractures and new vertebral deformities but not wrist fractures. J Bone Miner Res 1999; 14: 821-8; http://dx.doi.org/10.1359/jbmr.1999.14.5.821

47. Klotzbuecher CM, Ross PD, Landsman P, et al. Patients with prior fractures have an increased risk of future fractures: a summary of the literature and statistical synthesis. $J$ Bone Miner Res 2000; 15: 721-39; http://dx.doi.org/10.1359/jbmr.2000.15.4.721

48. Cummings SR, Nevitt MC, Browner WS, et al. Risk factors for hip fracture in white women. Study of Osteoporotic Fractures Research Group. N Engl J Med 1995; 332: 767-73; http:// dx.doi.org/10.1056/NEJM199503233321202

49. Kanis JA, Johnell O, De Laet C, et al. A meta-analysis of previous fracture and subsequent fracture risk. Bone 2004; 35: 375-82; http://dx.doi.org/10.1016/j.bone.2004.06.017

50. Ross PD, Davis JW, Epstein RS, et al. Pre-existing fractures and bone mass predict vertebral fracture incidence in women. Ann Intern Med 1991; 114: 919-23; http://dx.doi. org/10.7326/0003-4819-114-11-919

51. Black DM, Steinbuch M, Palermo L, et al. An assessment tool for predicting fracture risk in postmenopausal women. Osteoporos Int 2001; 12: 519-28; http://dx.doi.org/10.1007/ s001980170072 
52. Ismail A, Cockerill W, Cooper C, et al. Prevalent vertebral deformity predicts incident hip though not distal forearm fracture results from the European prospective osteoporosis. Osteoporos Int 2001; 12: 85-90; http://dx.doi.org/10.1007/s001980170138

53. Hasserius R, Johnell O, Nilsson BE, et al. Hip fracture patients have more vertebral deformities than subjects in population-based studies. Bone 2003; 32: 180-4; http://dx.doi. org/10.1016/S8756-3282(02)00951-1

54. Davis JW, Grove JS, Wasnich RD, et al. Spatial relationships between prevalent and incident spine fractures. Bone 1999; 24: 261-4; http://dx.doi.org/10.1016/S8756-3282(98)00176-8

55. Kanis JA, Johnell O, Oden A, et al. FRAX and the assessment of fracture probability in men and women from the UK. Osteoporos Int 2008; 19: 385-97; http://dx.doi.org/10.1007/ s00198-007-0543-5

56. Kanis JA, Johnell O, Oden A, et al. Smoking and fracture risk: a meta-analysis. Osteoporos Int 2005; 16: 155-62; http://dx.doi.org/10.1007/s00198-004-1755-6

57. Vestergaard P, Mosekilde L. Fracture risk associated with smoking: a meta-analysis analysis. J Intern Med 2003; 254: 572-83; http://dx.doi.org/10.1111/j.1365-2796.2003.01232.x

58. Chakkalakal DA. Alcohol-induced bone loss and deficient bone repair. Alcohol Clin Exp Res 2005; 29: 2077-90; http://dx.doi.org/10.1097/01.alc.0000192039.21305.55

59. Kanis JA, Johansson H, Johnell O, et al. Alcohol intake as a risk factor for fracture. Osteoporos Int 2005; 16: 737-42; http://dx.doi.org/10.1007/s00198-004-1734-y

60. Berg KM, Kunins HV, Jackson JL, et al. Association between alcohol consumption and both osteoporotic fracture and bone density. Am J Med 2008; 121: 406-18; http://dx.doi. org/10.1016/j.amjmed.2007.12.012

61. Hooyman JR, Melton LJ, Nelson AM, et al. Fractures after rheumatoid arthritis: a populationbased study. Arthritis Rheum 1984; 27: 1353-61; http://dx.doi.org/10.1002/art.1780271205

62. Ørstavik RE, Haugeberg G, Mowinckel P, et al. Vertebral deformities in rheumatoid arthritis: a comparison with population-based controls. Arch Intern Med 2004; 164: 420-5; http:// dx.doi.org/10.1001/archinte.164.4.420

63. Van Staa TP, Geusens P, Bijlsma JW, et al. Clinical assessment of the long-term risk of fracture in patients with rheumatoid arthritis. Arthritis Rheum 2006; 54: 3104-12; http:// dx.doi.org/10.1002/art.22117

64. Harrison BJ, Hutchinson CE, Adams J, et al. Assessing periarticular bone mineral density in patients with early psoriatic arthritis or rheumatoid arthritis. Ann Rheum Dis 2002; 61: 1007-11; http://dx.doi.org/10.1136/ard.61.11.1007

65. Cooper C, Carbone L, Michet CJ, et al. Fracture risk in patients with ankylosing spondylitis: a population based study. $J$ Rheumatol 1994; 21: 1877-82;

66. Vosse D, Landewé R, Van Der Heijde D, et al. Ankylosing spondylitis and the risk of fracture: results from a large primary carebased nested case control study. Ann Rheum Dis 2009; 68: 1839-42; http://dx.doi.org/10.1136/ard.2008.100503

67. Womack JA, Goulet JL, Gibert C, et al. Increased Risk of Fragility Fractures among HIV Infected Compared to Uninfected Male Veterans. PLoS ONE 2011; 6: e17217; doi:10.1371/ journal.pone.0017217

68. Yin MT, Shi Q, Hoover DR, et al. Fracture incidence in HIV-infected women: results from the Women's Interagency HIV Study. AIDS 2010; 24: 2679-86; doi:10.1097/ QAD.0b013e32833f6294

69. Young B, Dao CN, Buchacz K, et al. Increased Rates of Bone Fracture Among HIV-Infected Persons in the HIV Outpatient Study (HOPS) Compared With the US General Population, 2000-2006. Clin Infect Dis 2011; 52: 1061-8; http://dx.doi.org/10.1093/cid/ciq242

70. Cazanave C, Dupon M, Lavignolle-Aurillac V, et al. Reduced bone mineral density in HIV-infected patients: prevalence and associated factors. AIDS 2008; 22: 395-402; http:// dx.doi.org/10.1097/QAD.0b013e3282f423dd.

71. Gallant JE, Staszewski S, Pozniak AL, et al. Efficacy and safety of tenofovir DF vs stavudine in combination therapy in antiretroviral-naive patients: a 3-year randomized trial. JAMA 
2004; 292: 191-201; http://dx.doi.org/10.1001/jama.292.2.191

72. McComsey GA, Kitch D, Daar ES, et al. Bone mineral density and fractures in antiretroviral-naïve persons randomized to receive abacavir-lamivudine or tenofovir disoproxil fumarate-emtricitabine along with efavirenz or atazanavir-ritonavir: Aids Clinical Trials Group A5224 s, a substudy of ACTG A5202. J Infect Dis 2011; 203: 1791-801; http:// dx.doi.org/10.1093/infdis/jir188

73. Mondy K, Yarasheski K, Powderly WG, et al. Longitudinal evolution of bone mineral density and bone markers in human immunodeficiency virus-infected individuals. Clin Infect Dis 2003; 36: 482-90; http://dx.doi.org/10.1086/367569

74. van Vonderen MG, Lips P, van Agtmael MA, et al. First line zidovudine/lamivudine/ lopinavir/ritonavir leads to greater bone loss compared to nevirapine/lopinavir/ritonavir. AIDS 2009; 23: 1367-76; http://dx.doi.org/10.1097/QAD.0b013e32832c4947

75. van Vonderen MG, Mallon P, Murray B, et al. Changes in Bone Biomarkers in ARVnaïve HIVRMen Randomized to NVP/LPV/r or AZT/3TC/LPV/ $r$ Help Explain Limited Loss of Bone Mineral Density over the First 12 Months after ART Initiation. 18th Conference on Retroviruses and Opportunistic Infections. Boston, 2011

76. Ofotokun I, Weitzmann N, Vunnava A, et al. HAART-induced Immune Reconstitution: A Driving Force Behind Bone Resorption in HIV/AIDS. 18th Conference on Retroviruses and Opportunistic Infections. Boston, 2011

77. Bedimo R, Maalouf NM, Zhang S, et al. Osteoporotic fracture risk associated with cumulative exposure to tenofovir and other antiretroviral agents. AIDS 2012; 26: 825-31; http:// dx.doi.org/10.1097/QAD.0b013e32835192ae

78. Johansson H, Oden A, Johnell Oet al. Optimization of BMD measurements to identify high risk groups for treatment - a test analysis. J Bone Miner Res 2004; 19: 906-13; http:// dx.doi.org/10.1359/jbmr.2004.19.6.906

79. Krege JH, Wan X, Lentle BC, et al.; CaMos Research Group. Fracture risk prediction: importance of age, BMD and spine fracture status. Bonekey Rep 2013; 2: 404; http://dx.doi. org/10.1038/bonekey.2013.138 